\title{
Novel Quad-band Patch Antenna Design for Wireless Communications in 2.4, 5.2, 5.6 and 5.8 GHz Bands using Genetic Algorithm Optimization
}

\author{
${ }^{1}$ Jayasinghe JMJW, ${ }^{2}$ Uduwawala DN \\ ${ }^{1,2}$ Department of Electrical and Electronic Engineering \\ University of Peradeniya, Sri Lanka \\ E-mail: jeevni98@yahoo.com \\ ${ }^{1}$ Department of Electronics \\ Wayamba University of Sri Lanka, Sri Lanka
}

\begin{abstract}
This paper presents the design of a novel quad band patch antenna for wireless communications in $2.4,5.2,5.6$ and $5.8 \mathrm{GHz}$ Bands. Antennas operating in these bands are available in various sizes and used in small hand-held devices as well as in wireless local area networks. A substrate with dielectric constant 3.2 and thickness $3.175 \mathrm{~mm}$ is used for the design. The patch dimensions $(40 \times 30 \mathrm{~mm})$ are similar to that of the conventional rectangular patch for the center frequency of the lowest frequency band which is $2.4 \mathrm{GHz}$. The antenna is fed by a $50 \Omega$ coaxial cable. Genetic algorithm optimization (GAO) is used to optimize the patch geometry and feed position. Simulations are carried out by using HFSS. The optimized antenna resonates at $2.4 \mathrm{GHz}$ with fractional bandwidth of $4.1 \%$ and at $5 \mathrm{GHz}$ bands with fractional bandwidth of $33.5 \%$.
\end{abstract}

Keywords: Bluetooth, Fractional bandwidth, GAO, quad-band, UNII.

\section{Introduction}

The tremendous growth of mobile communication systems opens a huge demand to new kind of antennas such as small antennas, multi-frequency antennas, broadband antennas, etc. Patch antenna technology provides an attractive solution with low volume, low cost, simple planar configuration and low weight. It 
consists of three layers: a metallic layer with antenna element pattern, dielectric substrate and another metallic layer as the ground plane [1]. But patch antennas have some disadvantages such as narrow bandwidth, low efficiency and low gain. Therefore it is a challenging task to design small multi-frequency and broadband patch antennas.

Bluetooth $(2400-2483.5 \mathrm{MHz})$ is more of a personal productivity wireless technology, with a range of about 10 meters. It is an internationally-recognised Industrial, Scientific and Medical (ISM) band. The connections enabled by Bluetooth will be quite novel: headsets to cellular telephones; cellular telephones to portable computers; electronic wallets to point-of-sale systems; portable computers to Internet connections in airports or hotels, and on and on.

Recognizing the limitations of the $2.4 \mathrm{GHz}$ spectrum, licensing authorities around the world have allocated large blocks of spectrum in the $5 \mathrm{GHz}$ band for wireless communication. The $5 \mathrm{GHz}$ band is divided into several sections referred to as Unlicensed National Information Infrastructure (UNII) bands. UNII-1 (5150-5250 $\mathrm{MHz})$ band is designated for indoor operations. UNII-2 (5250-5350 MHz) and UNII-2 extended (5470-5725MHz) bands are for indoor and outdoor operations. UNII-3 (5725-5825MHz) band is assigned for use by ISM equipment, but which is also used by many other wireless devices.

Design of multi-frequency [4-12], broadband [4,12,13] and high directivity [4] patch antennas are illustrated in the literature. Different methods such as fractalshapes [4], dipoles [6], trapezoidal feed plate [7], monopole and shorted parasitic patch [8], cavity ground [9], U-shaped slot [10] and spiralling [11] etc. have been shown to be useful to design multiband antennas. Patch antenna designs which cover all four bands [6,7] or less out of them [8-11] are found in the literature. In quad band designs, the antenna size is large with $12.5 \mathrm{~mm}$ thickness in [6] and $9 \mathrm{~mm}$ thickness in [7]. [8] illustrates a triple band patch antenna operating only in 2.4, 5.2 and $5.8 \mathrm{GHz}$ bands. Only 2.4 and $5.2 \mathrm{GHz}$ bands are covered in [10] and [11]. The dual band patch antenna presented in [9], covers only 5.2 and $5.8 \mathrm{GHz}$ bands.

GAO is proposed as a powerful optimization technique for designing patch antenna [5, 13-16]. It is a robust, stochastic-based search method, which can handle the common characteristics of electromagnetic optimization problems that are not readily handled by other traditional optimization methods. GAO is used to increase the bandwidth [14], to design dual band patch antennas [5,15] and to design broadband patch antennas [13,16].

This paper presents a small novel quad band patch antenna for Bluetooth, UNII-1, UNII-2 and UNII-3 bands while keeping the antenna size small. GAO is used to optimize the patch geometry and the feed position simultaneously. Section 2 of this paper describes the methodology used for the design. Section3 presents the simulation results of the rectangular shaped conventional patch antenna and the optimized patch antenna. Finally conclusions are given. 


\section{Methodology}

Patch dimensions are $40 \times 30 \mathrm{~mm}$ and similar to that of a rectangular patch operating in the fundamental mode at the lowest frequency band which is Bluetooth [1]. The patch area is gridded into 40 cells as shown in Fig.1. Patch geometry is assumed to be symmetrical parallel to $\mathrm{x}$ axis (Fig1). Therefore, only a half of the patch is coded accordingly as genes in GAO procedure. First 20 genes of the chromosome are used to define the shape. Next four genes are used to define the feed position. The feed position is placed on the symmetrical axis. The solution is searched such that the reflection coefficient is kept below -6dB [17-18].

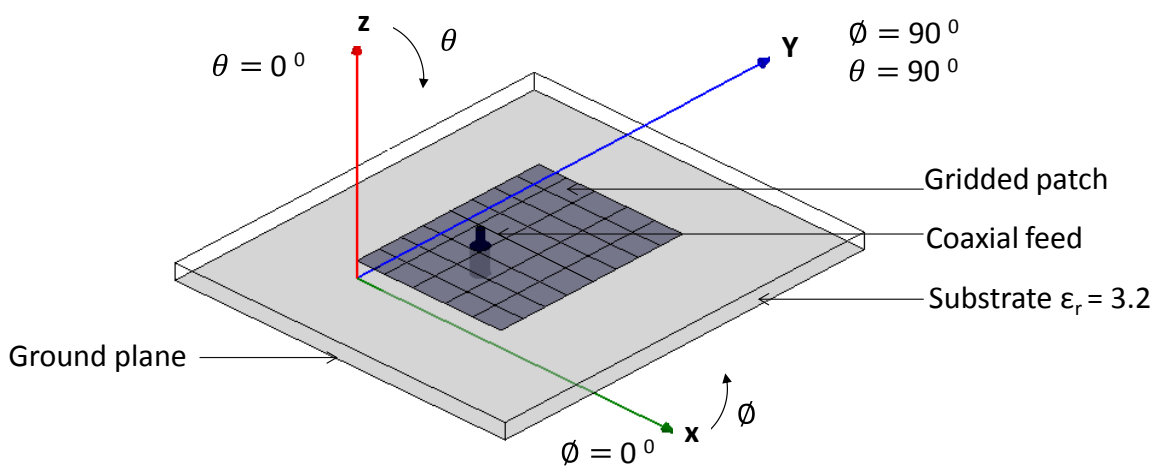

Fig.1: patch geometry

The population size is 20 chromosomes per generation and the used selection method is tournament selection. The probability of crossover is $100 \%$ and single point crossover method is used. One bit is mutated in $60 \%$ of the individuals within a generation. The percentage of the current generation that is to be replaced is $50 \%$. The temporary population size and parent population size are 20 . The temporary population is inserted into parent population, producing a temporarily expanded population which is 40 in size. Only 20 individuals are selected from that, based on the fitness value. As replacement of the least-fit individuals is used, the preservation of the fittest individuals is guaranteed.

\section{Results and Discussion}

\subsection{Simulation Results of The Rectangular Shaped Conventional Patch Antenna}

Initially a rectangular shape conventional patch antenna with same dimensions is designed and the bandwidth performance is checked for comparison. The coaxial feed is placed on the symmetrical axis so as to give the best bandwidth (fig.2a). It resonates at $2.4 \mathrm{GHz}$ as shown in Fig. $2 \mathrm{c}$. There is no resonance around $5 \mathrm{GHz}$, but shows an unwanted resonance around $4 \mathrm{GHz}$. 


\subsection{Simulation Results of the Optimized Patch Antenna}

The optimized design (fig.2b) resonates at two frequencies covering all four bands. At $2.4 \mathrm{GHz}$ band, the optimized design operates from $2.4 \mathrm{GHz}$ to $2.5 \mathrm{GHz}$ (Fig.2c). The fractional bandwidth is $4.1 \%$.

At the upper band it shows multi-frequency broadband characteristics by operating in the region from $4.85 \mathrm{GHz}$ to $6.8 \mathrm{GHz}$ covering UNII-1, UNII-2 and UNII-3. The fractional bandwidth is $33.5 \%$.

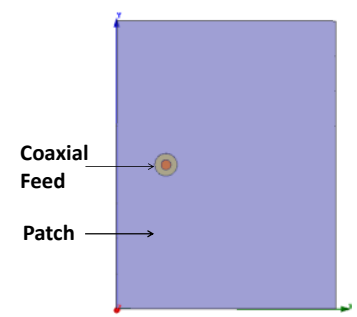

(a)

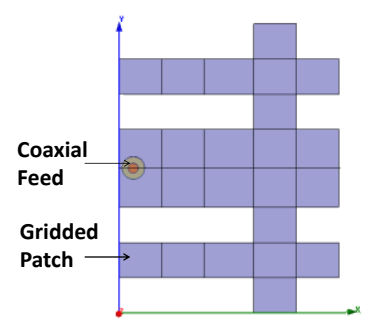

(b)

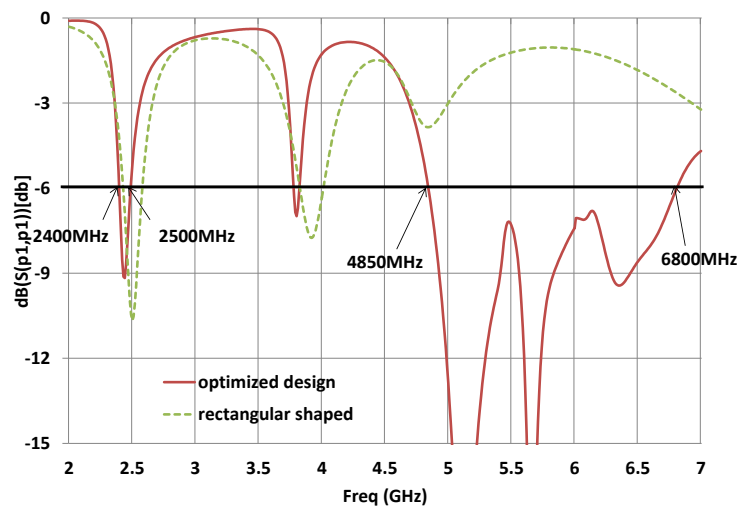

(c)

Fig.2: simulation results (a) patch geometry of the conventional patch (b) patch geometry of the optimized design (c) reflection coefficient plots

At $2.4 \mathrm{GHz}$ band, the patch antenna has maximum radiation perpendicular to the patch plane. At the other three bands, the maximum radiation is along the patch plane (Fig.3a). The maximum gain at $2.4 \mathrm{GHz}$ band varies between 6-7dB (Fig.3b). At UNII bands, the maximum gain changes between 8-14dB Fig.3c).

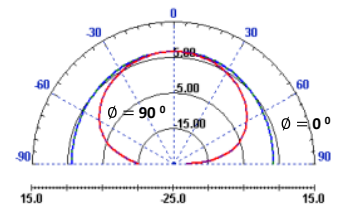

Bluetooth

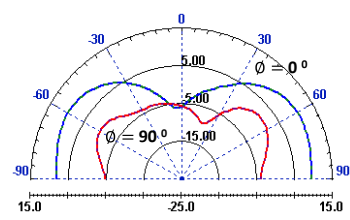

UNII-1

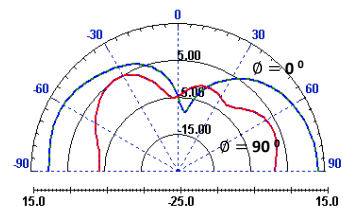

UNII-2

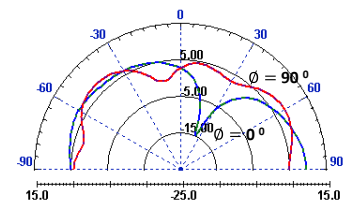

UNII-3

(a) 


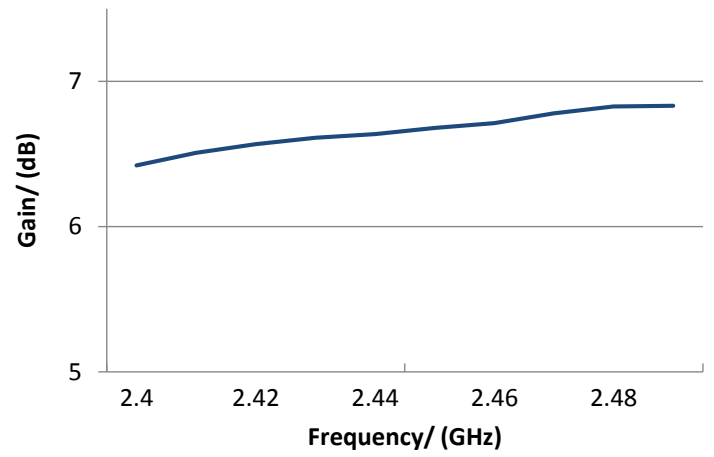

(b)

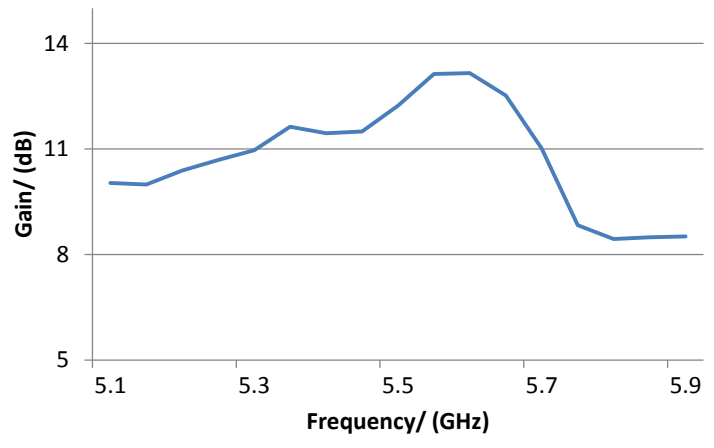

(c)

Fig.3: simulation results of the optimized design (a) radiation pattern at the center of each band (b) variation of gain at the Bluetooth band (c) variation of gain at UNII

\section{Conclusion}

Conventional patch antennas show narrowband characteristics. There is no specific method to design multi-frequency or wideband patch antennas. In this paper, GAO has been used to design a small single probe feed patch antenna operates in Bluetooth, UNII-1, UNII-2 and UNII-3 bands. The patch geometry and feed position have been optimized to operate as a quad-band patch antenna. The simulations have been carried out by using HFSS. Results show that multi band patch antennas can be designed by using GAO without increasing antenna dimensions.

\section{References}

[1] Balanis, C, Antenna theory and design, 2nd ed., Willey \& sons, (1997)

[2] J. Anguera, "Fractal and Broad-Band techniques on Miniature, Multifrequency, and High-Directivity Microstrip Patch Antennas", Ph.D Dissertation at Universitat Politècnica of Catalunya, Barcelona, Spain, July 2003

[3] W. Kwak, S.O. Park, J.S. Kim, "A folded planer inverted-F antenna for GSM/DCS/Bluetooth Triple-Band application", IEEE Antennas and propagation letters, Vol 5, (2006), pp. 18-21.

[4] A. Cabedo, J. Anguera, C. Picher, M. Ribó and C. Puente, "Multiband handset antenna combining a PIFA, slots and ground plane modes", IEEE trans. Antennas and propagation, Vol. 57, No 9, (2009), pp. 2526-2533. 
[5] J.M.J.W. Jayasinghe, D.N. Uduwawala, "Design of a Dual Band Antenna for Bluetooth and HIPERLAN2 Applications using Genetic Algorithm Optimization", 6th IEEE International Conference on Industrial and Information Systems, (2011), pp. 283 - 287.

[6] R. Li, T. Wu, and M. Tentzeris, "A Dual-Band Unidirectional Coplanar Antenna for 2.4-5-GHz Wireless Applications", IEEE Microwave Conference, (2008), pp.1-4

[7] P. Nepa, G. Manara, A.A. serra and G. Nenna, "Multiband PIFA for WLAN mobile terminals", IEEE trans. Antennas propagate., Vol 4., (2005), pp. 349-350.

[8] J. Jan, L. Tseng, "Small planer monopole antenna with a shorted parasitic inverted-L wire for wireless communications in the $2.4,5.2$ and $5.8 \mathrm{GHz}$ bands". IEEE trans. Antennas propagate., Vol 52., No. 7, (2004), pp. 19031905.

[9] S.W. Su, K.L. Wong, Y.T. Cheng and W.S. Chen, "High-gain Broadband Patch Antenna with a cavity ground for 5-GHz WLAN operation", Microwave and optical technology letters, Vol. 41, (2004), pp. 397-399

[10] P. Salonen, M. Keskiilammi and M. Kivikoski, "Singhe-feed Dual-Band planar inverted-f antenna with U-Shaped slot", IEEE trans. Antennas propagate. , Vol 48., No. 8, (2000), pp. 1262-1264.

[11] Y. Wang, M. Lee and S. Chung, "Two PIFA related miniaturized dual-band antenna", IEEE trans. Antennas propagate. , Vol 55., No. 3, (2007), pp. 805811. 